\title{
The behaviour of composites, glass ionomers and compomers in erosive conditions - in vitro study
}

\author{
Borș Andreea, Molnar-Varlam Cristina, Székely Melinda \\ Department of Morphology of Teeth and Dental Arches; Technology of Dental Prosthesis and Dental Materials, Faculty of Dental Medicine, University of \\ Medicine and Pharmacy, Tîrgu Mureș
}

\begin{abstract}
Objective: The aim of this in vitro study was to evaluate the influence of erosive conditions on the wear resistance of aesthetic direct restorative materials. Methods: Six dental filling materials were tested: two composites (Filtek Z550 and X-tra fil), two compomers (Dyract Extra and Twinky Star) and two glass ionomers (Ketac Molar and Fuji II LC). Twenty disks $(10 \mathrm{~mm} \times 2 \mathrm{~mm})$ of each material were prepared ( $\mathrm{n}=120)$ and kept in artificial saliva at $37^{\circ} \mathrm{C}$ for 24 hours. Specimens were cycled in acidic soft drink (Coca-Cola) $5 \times /$ day, for 5', over 30 days. Initial surface roughness ISR (Ra- $\mu \mathrm{m})$ and final surface roughness FSR were measured using a profilometer. The wear rate was calculated as difference of final minus the initial roughness ( $\triangle \mathrm{SR}=\mathrm{FSR}$-ISR). For statistical analysis t-test and one-way ANOVA test were used by GraphPad Prism version 5.03 statistical software. The level of significance was set at $p<0.05$. Results: The erosive wear rates (mean $\pm S D, \mu m)$ after exposure to acidic beverage were: $0.30 \pm 0.03$ (Ketac Molar), $0.28 \pm 0.04$ (Fuji II LC), $0.27 \pm 0.00$ (Filtek Z550), $0.23 \pm 0.01$ (X-tra fil), $0.20 \pm 0.00$ (Twinky Star) and $0.14 \pm 0.01$ Dyract Extra, respectively. There were significant differences between the tested materials $(p<0.05)$. Conclusions: Dental filling materials had different behaviour under the same erosive condition, however all investigated aesthetic restorative materials showed surface degradation. These findings suggest that erosive wear resistance of tooth coloured restoratives could influence their longevity in intraoral acidic conditions. Acknowledgements: The study was supported by the Internal Research Grant no. 5/30.01.2013 of the University of Medicine and Pharmacy of Tîrgu Mureș.
\end{abstract}

Keywords: compomer, composite, glass ionomer, erosive wear, in vitro

Received: 19 August 2014 / Accepted: 17 October 2014

\section{Introduction}

Nowadays, a remarkable increase has been reported in the incidence of non-carious lesions in the general population, especially dental erosion [1]. Factors as bulimia, gastric acid reflux, acidic medicines and frequent acidic diet exposure represent significant factors in the development of dental erosion [2-4]. The global increase in the ingestion of acidic beverages, such as soft drinks and fruit juices is one of the main causes of the high prevalence of dental erosion [5].

Tooth-coloured direct restoratives are often used in erosive lesions for enamel and dentin rehabilitation. Physical and chemical properties of dental filing materials are indicators that predict their clinical performance. The roughening of the surface caused by wear and chemical degradation may affect gloss and consequently increase plaque retention, thus decreasing the longevity of the restoration [6].

Therefore, failure or success of aesthetic restorations depends on their behaviour under still persisting erosive conditions. The critical oral environment conditions, i.e., $\mathrm{pH}$ changes and humidity, may increase dental materials biodegradation over time [7]. This is a complex process that may lead a composite, a glass ionomer or a compomer polymer matrix to collapse, causing several problems such as filler-polymer matrix debonding [8], release of residual monomers [9]. This process may deteriorate the chemical and mechanical properties of the material and reduce the clinical life of resin restorations.

Previous studies concerning dental filling materials susceptibility to common erosive agents degradation have shown that acidic drinks (such as wine, soft drinks) and mouth rinses have varied degrees of damage on auto- and light-cured composite resins $[6,10]$.

However, only few studies have reported data regarding the potential erosive effects of these agents on the toothcoloured restoratives such as the glass ionomer cements (GICs), the resin modified GICs (RMGICs), quartz or glass filler containing resin composites (CRs) and polyacid modified composite resins (compomers) [6].

The purpose of this study was to evaluate the effects of acidic beverages, under $\mathrm{pH}$-cycling conditions, on the surface roughness of six aesthetic direct restorative materials and to compare their depth of bulk loss.

The tested null hypothesis was that exposure to an acidic soft drink in a pH-cycling model, would not influence the roughness and surface degradation of the evaluated dental restoratives. 


\section{Methods}

Six aesthetic dental filling materials were selected for the study: a universal nano-filler Filtek Z550 (3M St. Paul, MN, USA), a posterior composite X-tra fil (Voco GmbH, Cuxhaven, Germany), two compomers Dyract Extra (Dentsply/Caulk, Milford, DE, USA) and Twinky Star (Voco $\mathrm{GmbH}$, Cuxhaven, Germany), a glass ionomer filling material Ketac Molar (3M ESPE, Seefeld, Germany) and a resin-reinforced glass ionomer restorative Fuji II LC (GC America, Illinois).

All materials were polymerized according to manufacturers' instructions into plastic rings $(10 \mathrm{~mm}$ in diameter and $2 \mathrm{~mm}$ in thickness) to obtain specimens identical in size. These rings were slightly overfilled with the material, covered by a Mylar strip (Henry Schein; Melville, NY) and placed between two glass slides. The glass ionomer filling material was hand mixed and the rest of restoratives were polymerized on each side (exposure time 40 seconds) with a visible light curing unit (Demetron, Kerr, Orange, CA). The intensity of the light was verified with a radiometer (SDS Kerr, Orange, CA). The light was placed perpendicular to the specimen surface, at a distance of $1.5 \mathrm{~mm}$.

Twenty cylindrical specimens of each material were prepared $(n=20)$ in this manner, for a total of 120 specimens $(n=120)$. After polymerization the discs were kept immersed in artificial saliva (Bioxtra, Biopharm, Peschiera Borromeo, MI, Italy) at $37^{\circ} \mathrm{C}$. After 24 hours each group was cycled in Coca-Cola ${ }^{\oplus}$ beverage $5 \times /$ day, for 5 ', over 30 days. The acidic soft drink was employed at the temperature of consumption $4^{\circ} \mathrm{C}$. The specimens were kept immersed in artificial saliva at $37^{\circ} \mathrm{C}$ during the period between the cycles.

The average surface roughness of discs $(R a-\mu \mathrm{m})$ was measured using a profilometer (Surftest SJ 201, Mitutoyo Co, Kawasaki, Japan). Three roughness measurements were recorded for each specimen (cut-off length of 0.25 $\mathrm{mm}$ ). The mean value of these measurements was recorded as the surface roughness for each specimen.

Initial surface roughness ISR $(\mathrm{Ra}-\mu \mathrm{m})$ and at the $30^{\text {th }}$ day the final surface roughness FSR was measured. The wear rate was calculated, response variable was the difference of final minus the initial roughness ( $\triangle S R=F S R-I S R)$. For erosive wear resistance assessment, intermediate surface roughness were measured daily for every material.

Data analysis was accomplished by the GraphPad Prism version 5.03 statistical package (San Diego, CA, USA). Data were analyzed by analysis of variance (ANOVA) and Tukey post hoc tests followed by one sample t-test for statistical comparisons. The significance was preset to $5 \%$ $(p<0.05)$.

\section{Results}

The effect of exposure to $\mathrm{pH}$-cycling with intermittent immersion in carbonated acidic beverage (Coca Cola) on the surface roughness of the Ketac Molar, Fuji II LC Filtek Z550, X-tra fil, Twinky Star and Dyract Extra speci- mens following the thirty days test period is presented in Table I.

Table I. Summary of obtained data (mean value \pm SD, $\mu \mathrm{m}$ ) before and after exposure to Coca-Cola of the tested materials $(n=120)$.

\begin{tabular}{lccc}
\hline Material & $\begin{array}{c}\text { Initial surface } \\
\text { roughness (ISR) }\end{array}$ & $\begin{array}{c}\text { Final surface } \\
\text { roughness (FSR) }\end{array}$ & p value \\
\hline Ketac Molar & $0.23 \pm 0.04$ & $0.53 \pm 0.03$ & 0.0001 \\
Fuji II LC & $0.20 \pm 0.05$ & $0.48 \pm 0.04$ & 0.0001 \\
Filtek Z550 & $0.11 \pm 0.03$ & $0.38 \pm 0.03$ & 0.0001 \\
X-tra fil & $0.12 \pm 0.02$ & $0.35 \pm 0.03$ & 0.0006 \\
Twinky Star & $0.12 \pm 0.03$ & $0.32 \pm 0.01$ & 0.001 \\
Dyract Extra & $0.11 \pm 0.03$ & $0.25 \pm 0.04$ & 0.003 \\
\hline
\end{tabular}

Data analysis showed a statistically significant alteration in surface roughness $(\triangle S R)$ of the specimens. Ketac Molar $(p<0.0001)$ presented the highest depth loss, followed by Fuji II LC $(p<0.0001)$, Filtek Z550 $(p<0.0001)$, $X$-tra fil $(p<0.0006)$, Twinky Star $(p=0.001)$ and Dyract Extra $(p=0.003)$, respectively.

The ANOVA test indicated statistically significant differences with respect to surface roughness of each material $(p<0.05$, Fig 1$)$.

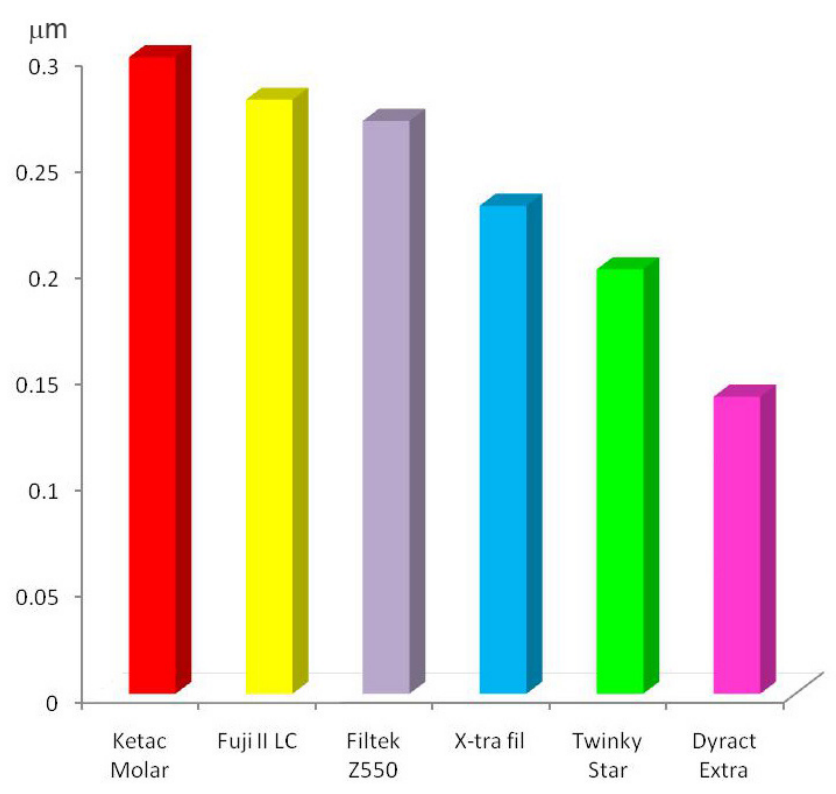

Fig. 1. Erosive wear rates ( $\mu \mathrm{m}, \Delta \mathrm{SR}=\mathrm{FSR}-\mathrm{ISR})$ of the tested dental materials.

Prior to exposure to acidic soft drink the glass ionomers had the highest surface roughness. Following intermittent immersion in Coca-Cola all materials experienced increasing in surface roughness over the tested period (Fig 2).

\section{Discussion}

Dental composites are considered the treatment of choice to seal tooth enamel and minimize further loss due to acid 


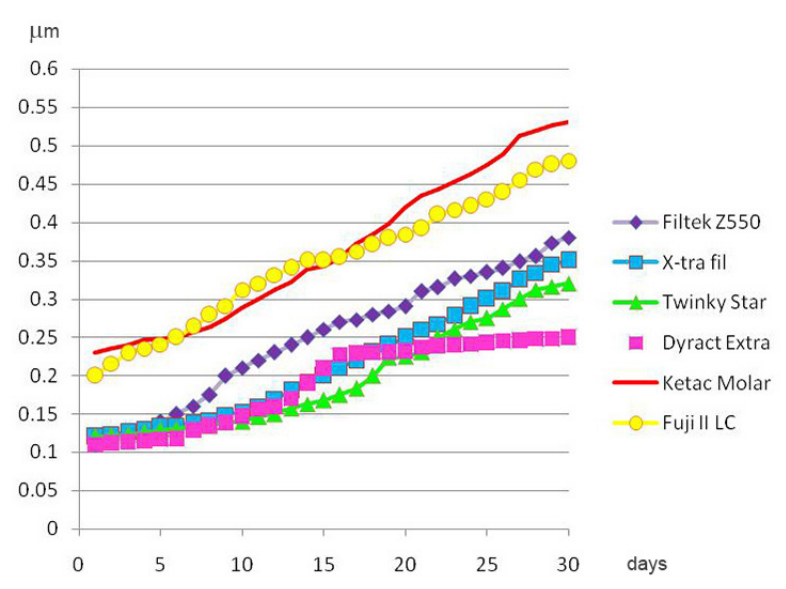

Fig. 2. Intermediate surface degradation over the tested period.

exposure [11]. The main advantages of composites are their aesthetic properties and high bond strength to the tooth structure. However, their success in use is sensitive to the application technique.

Glass ionomer cements are particularly useful in treating erosive and carious lesions in low stress areas, and for this reason many improvements in these materials have been developed, such as RMGIC, dual- and tri-cured GIC, and metal-reinforced GIC [12].

There are different methods that can be used to evaluate the erosion of dental materials: 1) a solubility test; 2 ) a method that measures the residual weight of a solution in which the dental material has been immersed; 3) a test which measures the depth loss of the material in a cavity filled with it [13]. In our study the erosion rate of three different types of tooth coloured dental filling materials were evaluated by measuring the depth loss of the surface.

Based on the results of this study, the anticipated null hypothesis was rejected. All tested materials showed statistically significant surface roughness increase in a cycling model with intermittent immersion in carbonated beverage (Coca-Cola). All compomers presented higher erosive wear resistance than resin composites and glass ionomers after cycling in acidic soft drink.

The erosive wear resistance of the tested universal nanofiller composite was less than that of the posterior composite.

Conventional glass ionomer showed higher erosive wear than resin-reinforced glass ionomer restorative under the same acidic conditions.

It is recognized that these tests may not represent the possible in vivo effects of dietary acids, and that the protection of saliva, dental pellicle and possibly plaque would reduce this effect [14]. However, the study set out to examine the worst case scenarios, such as might occur in a xerostomic patient with high consumption of acidic beverages.

In fact, the surface roughness is related to a combination of factors such as size, hardness and the percentage of surface area occupied by filler particles [15], the composition of the monomer [16], the degree of conversion of the resin matrix and the interaction matrix/particle, as well as the silane union stability [6].

These data are discordant of another study in the literature [17], which observed no significant increase on roughness means for composite resins and significant increase on surface roughness for compomers after one month of storage in Coca-Cola ${ }^{\circ}$ and after three months of storage in citric acid. This discrepancy in relation to the time factor can be attributed to the difference between the methodologies, because, in that, the specimens were immersed in solutions for the whole period of experiment and, in this one, it was tried to simulate 'real life' conditions by using the $\mathrm{pH}$-cycling study design.

Our results are similar to those of Chanothai et al. [18], who reported that composites resisted to acidic solutions better than a resin-reinforced glass ionomer (Fuji II LC). Ibrahim [19] also concluded that low $\mathrm{pH}$ beverages aggressively attacked RMGIC materials, while composite resins were relatively less affected. Reasons for the greater reduction in RMGIC include selective acid attack on the poly salt matrix between the residual particles and release of fluoride from the material following immersion in acidic environments [19].

Therefore, the relative susceptibility of different composite resins, polyacid modified resins and glass ionomers to erosive conditions warrants further investigation. More studies are necessary to assess the effect of various erosive formulations on various dental restorations.

\section{Conclusions}

According to the results obtained in the present study and considering the in vitro study restrictions, it can be concluded that:

- Surface degradation was observed in all investigated restorative materials in a $\mathrm{pH}$-cycling model with intermittent exposure to acidic soft drink.

- The tooth coloured dental filling materials had different behaviour under the same erosive conditions.

- Under the experimental acidic condition the erosive wear resistance of compomers was greater than that of the tested composites and glass ionomers, respectively.

- Dissimilar degradation as a result of exposure to low Ph, could be influenced by the different chemical composition and structure of the modern tooth-coloured dental restorative materials.

- The morphological surface differences of the tested dental restoratives may suggest possible variations of the clinical performance in intraoral erosive conditions.

\section{Acknowledgements}

The study was supported by the Internal Research Grant no. 5/30.01.2013 of the University of Medicine and Pharmacy of Tîrgu Mureş. 


\section{References}

1. Torres CP, Chinelatti MA, Gomes-Silva JM, Rizóli FA, Oliveira MA, PalmaDibb RG, et al. Surface and subsurface erosion of primary enamel by acid beverages over time. Braz Dent J 2010;21(4):337-345.

2. Machado C, Lacefield W, Catledge A. Human enamel nanohardness, elastic modulus and surface integrity after beverage contact. Braz Dent $J$ 2008;19(1):68-72.

3. Ulusoy C, Müjdeci A, Gökay $O$. The effect of herbal teas on the shear bond strength of orthodontic brackets. Eur J Orthod 2009;31(4):385-389.

4. Mandel L. Dental erosion due to wine consumption. J Am Dent Assoc 2005;136(1):71-75.

5. KhamverdiZ, Mohammad V, Shermin A, Mohammad H. Effect of a Common Diet and Regular Beverage on Enamel Erosion in Various Temperatures: An In-Vitro Study. Journ Dent Teheran 2013;10(5):411416.

6. Lepri CP, Palma-Dibb RG. Surface roughness and color change of a composite: Influence of beverages and brushing. Dental Materials Journal 2012;31(4):689-696.

7. Valinoti AC, Neves BG, Da Silva EM, Maia LC. Surface degradation of composite resins by acidic medicines and pH-cycling. J Appl Oral Sci 2008;16(4):257-265.

8. Bagheri R, Tyas MJ, Burrow MF. Subsurface degradation of resin-based composites. Dent Mater 2007;23:944-951.

9. Ruyter IE. Physical and chemical aspects related to substances released from polymer materials in an aqueous environment. Adv Dent Res 1995;9:344-347.
10. De Witte AMJC, De Maeyer EAP, Verbeeck RMH. Surface roughening of glass ionomer cements by neutral $\mathrm{NaF}$ solutions. Biomaterials 2003;24:1995-2000.

11. Jaeggi T., Gruninger A., Lussi A. Restorative therapy of erosion. Monographs Oral Sci 2006;20:200-214.

12. Nazish F, Syed Yawar AA, Fazal-Ur-Rehaman Q, Shahbaz AJ. Effect of different tetra pack juices on microhardness of direct tooth coloredrestorative materials. The Saudi Dental Journal 2013;25:29-32.

13. Lussi $A$ (ed). Dental erosion: from diagnosis to therapy. Monogr Oral Sci. vol 20, Ed. Karger, Basel, 2006, p 202.

14. Hara AT, Zero DT. The Potential of Saliva in Protecting against Dental Erosion. Monogr Oral Sci 2014;25:197-205.

15. Jaarda MJ, Wang R, Lang BR. A regression analysis of filler particle content to predict composite wear. J Prosthet Dent 1997;77:57-67.

16. Tanoue N, Matsumura M, Atsuta M. Wear and surface roughness of current prosthetic composites after toothbrush/dentifrice abrasion. J Prosthet Dent 2000;84:93-97.

17. Correr GM1, Bruschi Alonso RC, Baratto-Filho F, Correr-Sobrinho L, Sinhoreti MA, Puppin-Rontani RM. In vitro long-term degradation of aesthetic restorative materials in food-simulating media. Acta Odontol Scand 2012;70(2):101-108.

18. Chanothai $\mathrm{H}$, Boonlert K, Ureporn KL. Effect of naturally acidic agents on microhardness and surface micromorphology of restorative materials. Eur J Dent 2011;5:89-100.

19. Ibrahim $\mathrm{MH}$. Effects of various beverages on hardness, roughness, and solubility of esthetic restorative materials. J EsthetRestor Dent 2011;23:315-323. 